\title{
CONDIÇÕES DE QUALIDADE DAS REDES MUNICIPAIS DE ENSINO FUNDAMENTAL NO PARANÁ
}

http://dx.doi.org/10.5902/2318133864611

\author{
Gabriele Ferreira Barbosa ${ }^{1}$
}

\begin{abstract}
Resumo
O objetivo do presente artigo é analisar o panorama das condições de qualidade de oferta do ensino fundamental no Paraná, com delimitação às informações das escolas de anos iniciais das redes municipais de ensino para o ano de 2017. O método de análise quantitativa empregado foi o índice de condições de qualidade. O estudo demonstra regularidade de condições de qualidade em metade das redes municipais, a outra metade da amostra representa os municípios com os melhores e piores resultados, evidenciando um cenário de desigualdade intraestadual em termos de condições de qualidade. Ademais, os dados apresentados revelam a necessidade da ação da política educacional na forma do provimento do cargo de diretor, nos salários dos professores, bem como nas condições materiais das escolas.

Palavras-chave: condições de qualidade; ensino fundamental; políticas educacionais.
\end{abstract}

\section{QUALITY CONDITIONS OF MUNICIPAL SYSTEMS OF ELEMENTARY EDUCATION IN PARANÁ}

\begin{abstract}
:
The objective of this paper is to analyze the elementary school quality condition panorama in Paraná, delimiting information from schools in the early years of municipal education for the year 2017. The quantitative analysis method used was the quality conditions index. The study demonstrates the regularity of quality conditions in half of the municipal systems, the other half of the sample represents the municipal systems with the best and worst results, showing a scenario of intra-state inequality in terms of quality conditions provision. Furthermore, the data presented reveal the need for action by an educational policy in the form of filling the position of school principal, in teachers' salaries, as well as in the material conditions of schools.
\end{abstract}

Key-words: quality conditions; elementary school; educational policies.

1 Universidade Federal do Paraná, Brasil. E-mail: gabi.ferbar@hotmail.com. 


\section{Introdução}

avanço vivido nas últimas décadas no Brasil em termos de acesso e cobertura na educação básica tem dialogado e suscitado novas demandas relacionadas a efetivação da política educacional, daí a crescente discussão acerca da qualidade da oferta. As conquistas e ganhos associados à universalização do ensino fundamental abriram caminho para novos desafios que trazem para o campo de pesquisa a indispensabilidade de pensar e discutir a existência ou não de condições de qualidade escolar que possibilitem melhores condições de aprendizagem.

O termo qualidade e a forma como é abordado na literatura apresenta limitações e dissensos, tendo em vista que se trata de um conceito polissêmico, conforme destaca Oliveira e Araújo (2005). Ademais, a discussão de qualidade educacional não é nova (Gouveia, Souza, Schneider, 2011) e há diversas formas de enfrentar tal debate. Mas, afinal, o que significa qualidade? Etimologicamente Cury (2014) aponta que

o termo qualidade advém do latim qualitas, mas cuja procedência mais funda é a de poiótês do grego e que significa um título definidor de uma categorização ou classificação. De certo modo, estamos no campo de um atributo distintivo de um bem que passa a se apresentar com uma característica particular além da comum. Por vezes, essa distinção costuma ser assinalada com uma adjetivação como no caso de qualidade social, qualidade total, entre outras. (p. 1054)

Nesse sentido, qualidade parece ser um atributo e particularidade que confere valor superior a um determinado produto, sujeito ou serviço e que o distingue dos seus semelhantes. Por sua vez, quando se olha para um produto ou serviço vendido pelo mercado o cliente pode utilizar diversas métricas para caracterizá-lo como de qualidade ou não. Assim, a qualidade também pode ser um conceito multidimensional.

Furtado (2009) também destaca que qualidade é associada a um sentido de excelência aplicável aos processos das corporações privadas que, diante da acirrada competitividade do mercado, buscam a melhoria de produtividade, bem como a maximização dos resultados e diminuição dos prejuízos. Nesse sentido, muitas vezes o termo qualidade é erroneamente utilizado, tendo em vista que tal noção se trata de eficiência e não de qualidade.

E no campo educacional o que significa educação de qualidade? Essa pergunta possui múltiplas possibilidades de resposta de acordo com as diferentes visões de mundo, experiências, valores e posição social dos sujeitos. Entretanto, Oliveira e Araújo (2005) entendem que ao longo da história da educação brasileira é possível observar que "três significados distintos de qualidade foram construídos e circularam simbólica e concretamente na sociedade" (p. 8), os quais trataremos a seguir.

\section{Qualidade conforme a literatura educacional especializada}

A partir da Constituição Federal de 1988, alterada pela emenda constitucional n. 59 de 2009, a educação básica, obrigatória e gratuita dos 4 aos 17 anos, foi considerada direito público subjetivo de todos, inclusive àqueles que não tiveram acesso na idade própria. A positivação legal do direito à educação vem acompanhada não apenas pelo direito de acesso ao ensino, mas também a garantia de que este será ministrado tendo 
como base, entre outros princípios, a garantia de padrão de qualidade (inciso VII do artigo 206). O status constitucional dado ao tema da qualidade do ensino é exclusividade da Carta de 1988, não encontrando antecedentes na história constitucional brasileira. A determinação da CF é, ainda, endossada pelo art. $4^{\circ}$ inciso IX da LDB ao dispor "padrões mínimos de qualidade de ensino, definidos como a variedade e quantidade mínimas, por aluno, de insumos indispensáveis ao desenvolvimento do processo de ensinoaprendizagem."

É certo que estes avanços em termos legais da titularidade ao direito à educação e o aumento em termos de acesso e cobertura na educação básica tem ido ao encontro de outros debates relacionados a qualidade da oferta do ensino que também já era objeto da CF 1988. Por sua vez, a compreensão do que se trata de fato a qualidade do ensino, seja em termos práticos ou conceituais passou por diversas alterações ao longo da história, sendo que até hoje não há um consenso, "uma vez que a diversidade de visões de mundo conduz à elaboração de expectativas, projeções e ideais de qualidade diferenciados" (Camargo et al., 2006, p. 23).

Sendo então a qualidade um conceito polissêmico (Cury, 2014), uma vez que envolve múltiplas significações, é importante discutir de que formas, ao longo das últimas décadas, o debate da qualidade do ensino vem sendo enfrentado. Oliveira e Araújo (2005) revelam que no Brasil este tema foi percebido de três formas distintas. Num primeiro momento ele se relaciona com a ampliação das oportunidades de acesso aos serviços educacionais, uma vez que a oferta era insuficiente. Isso significa que a qualidade estava intimamente ligada à sua dimensão quantitativa (Beisiegel, 2005).

Nesse sentido, a qualidade estava associada à garantia de igualdade formal de acesso a níveis de ensino à totalidade da população, tendo em vista que havia escassez de vagas. Porém, esta demanda de acesso e de igualdade em relação àqueles que já estavam dentro da escola, não carregava a preocupação, seja por parte dos que estavam demandando - sociedade - ou oferecendo - Estado -, se essa oferta educacional se efetivaria de forma adequada e para, além disso, se ela se ajustaria à medida dos desejos e expectativas de cada um.

Num segundo momento, passada a ampliação do acesso e da rede de escolas da educação básica, a qualidade foi caracterizada pela ideia de fluxo escolar. Conforme destacam Oliveira e Araújo (2005), a expansão de vagas levou a novos desafios e disputas no interior da escola. Se antes estes alunos não chegavam a escola, agora eles estavam de forma crescente sendo incorporados ao sistema escola e os obstáculos relacionados à permanência com sucesso configurava-se como o grande desafio da qualidade.

A qualidade aferida mediante os testes padronizados em larga escala, nos moldes do Sistema Nacional de Avaliação da Educação Básica - Saeb - configura-se como o terceiro momento da qualidade educacional no Brasil. Tais avaliações também constituem um instrumento que entra em consonância com a nova ordem global instituída nos anos de 1990 de cunho gerencial, voltada para a modernização e eficiência do aparato burocrático do Estado (Silva, 2009).

Convém destacar que as distintas formas de interpretar qualidade educacional não são excludentes entre si, o que implica pensar que cada nova versão da qualidade não substitui inteiramente a anterior (Enguita, 1997). Antes, é necessário compreender que 
em se tratando a educação um campo permeado por disputas e dissensos, atores individuais e coletivos com interesses distintos concorrem em torno de uma mesma palavra de ordem, neste caso, a qualidade. Sobre estas disputas, Souza (2016) comenta que

a qualidade na educação não é uma referência passível de ser dimensionada em uma métrica atemporal e as condições para que seja conquistada tampouco são uniformes em qualquer tempo, espaço e dimensão. Ainda que a qualidade possa ser representada no crescimento e no aperfeiçoamento da aprendizagem, quão mais/melhor formado ou aperfeiçoado deve ser o estudante (ou o seu domínio de conhecimento e formação) é algo extremamente complexo e, por isso mesmo, em disputa na política educacional. (p. 15)

Sendo, portanto, um conceito em disputa, a qualidade educacional tem sido objeto de demandas que estão sendo levadas ao Poder Judiciário, como explicam Taporosky e Silveira (2018) em recente estudo sobre a judicialização da educação infantil. As autoras revelam que, embora ainda sejam restritas as análises das condições de oferta do ensino por parte do poder judiciário, são crescentes os litígios que envolvem a necessidade de que o direito à educação seja cumprido, não apenas mediante a ampliação de vagas, mas com garantia de padrões mínimos de qualidade, o que implica na crescente necessidade de regulação jurídica do tema (Ximenes, 2014).

Nesse contexto é possível afirmar que a literatura especializada da área tem enfrentado de diversas formas o debate da qualidade educacional, reforçando a dimensão polissêmica do tema (Cury, 2014). Entretanto, cabe ainda destacar que a opção teórica deste artigo se vale do conceito 'condições de qualidade' que, segundo Gouveia, Souza e Schneider (2011), significa compreender a qualidade "como as condições disponíveis para a realização do ensino e para a efetivação da aprendizagem, dimensionáveis em indicadores quantificáveis" (p. 115). Entre outras palavras, pensar em condições de qualidade implica em pensar os aspectos essenciais para a efetivação de um projeto educacional que visa a garantir o pleno desenvolvimento humano (Gouveia, Polena, 2015).

Assim, a fim de investigar a efetividade das políticas educacionais, no que se refere à qualidade da oferta do ensino de maneira focalizada e sensível a realidade local, foram analisadas as condições materiais das escolas, as condições do trabalho docente e as condições de gestão das redes municipais de ensino fundamental no Paraná no ano de 2017, de modo a quantificar e traduzir, a partir do índice de condições de qualidade as objetivas condições em que o ensino tem sido ofertado neste estado da federação.

\section{Metodologia}

A metodologia utilizada para essa pesquisa - o Índice de Condições de Qualidade ICQ - foi desenvolvido no âmbito de pesquisa do Núcleo de Políticas Educacionais da Universidade Federal do Paraná intitulada Políticas educacionais e qualidade do ensino (Nupe, 2007) e tem como objetivo a elaboração de uma ferramenta de auxílio para a avaliação da relação entre a política e a qualidade da educação (Gouveia, Souza, Schneider, 2011). 
Optou-se pelo uso dos questionários de contexto que acompanham o Saeb como fonte para a elaboração do ICQ, pois estes apresentam informações socioeconômicas de alunos, informações sobre o perfil e as condições de trabalho do professor e de diretores de escola e sobre as condições materiais das escolas. Ademais, o ICQ foi elaborado a partir de três dimensões reconhecidas na literatura como fundamentais para o trabalho pedagógico e as informações realmente disponíveis nos questionários de contexto do Saeb. Assim, ele é constituído por três partes: Índice de Condições Materiais da Escola ICM -, Índice de Condições do Professor - ICP - e Índice de Condições de Gestão - ICG. O ICM foi formado a partir do questionário respondido pelo aplicador da prova. Já o ICP por meio das questões destinadas aos professores de Língua Portuguesa e Matemática das turmas avaliadas e o ICG pelo questionário respondido pelo diretor ${ }^{2}$.

Esta pesquisa, por sua vez, concentra-se na investigação das condições de qualidade das escolas públicas de ensino fundamental do Paraná. Assim, foram utilizadas as respostas dos questionários de contexto da Prova Brasil da edição de 2017, aplicadas às turmas de $5^{0}$ ano do ensino fundamental para este Estado da federação, sendo analisados os dados de 2.527 escolas e 7.897 professores. Portanto, refere-se a um estudo de cunho quantitativo. Optou-se por trabalhar de forma agregada com os dados das escolas urbanas e rurais, tendo como base a pesquisa de Silva (2017) que revelou que a manutenção integrada das escolas por localização na avaliação do ICQ no país não alterou significativamente o quadro de resultados.

Cada resposta das perguntas dos questionários ${ }^{3}$ foi quantificada em relação ao seu conteúdo, sendo que todas as quantificações sejam das variáveis, dos indicadores parciais ou do próprio ICQ foram mensuradas de 0 a 1 . Assim, a fórmula do ICQ foi definida para esta pesquisa como segue.

Figura 1 -

Fórmula do ICQ.

\section{$I C Q=I C P^{*} 0,6+I C M E^{*} 0,3+I C G^{*} 0,1$}

$$
\mathrm{ICP}=\frac{\mathrm{V} 1^{\star} 2+\mathrm{V} 2^{\star} 4+\mathrm{V} 3+\mathrm{V} 4}{8} \quad I C M E=\frac{V 1+V 2+V 3^{\star} 2+V 4^{\star} 3}{7} \quad I C G=\frac{V 1^{\star} 5+V 2^{\star} 2+V 3^{\star} 2+V 4}{10}
$$

Fonte: adaptado de Silva (2017).

O ICP é composto por:

$\mathrm{V} 1$ = Indicador de escolaridade

\footnotetext{
2 Para visualizar na íntegra os questionários de contexto do Saeb fomentadores do ICQ acessar: $<$ http://provabrasil.inep.gov.br>.

${ }_{3}^{3}$ As questões dos questionários de contexto da Prova Brasil selecionadas para a composição do ICQ, bem como a quantificação das respostas de cada uma delas estão descritas em Silva (2017).

\begin{tabular}{|l|c|c|c|c|}
\hline Regae: Rev. Gest. Aval. Educ. & Santa Maria & v. 10 & n. 19 & e64611, p. 1-15
\end{tabular} 2021
} 
V2 = Indicador de salário por 40 Horas

V3 = Indicador de experiência

V4 = Indicador de situação trabalhista

O ICME é composto por:

V1 = Indicador de conservação das condições físicas

V2 = Indicador de iluminação e ventilação

V3 = Indicador para computadores e internet

V4 = Indicador para equipamentos eletrônicos

O ICG é composto por:

V1 = Indicador de Salário do diretor

$\mathrm{V} 2$ = Indicador de forma de provimento

V3 = Indicador de conselho de escola

V4 = Indicador de projeto político-pedagógico

Para a definição dos pesos atribuídos para cada variável Gouveia, Souza e Schneider (2011) se basearam em dois aspectos: um quantitativo e outro qualitativo. Em relação ao primeiro, testes das Correlações de Pearson realizadas entre os indicadores parciais e as proficiências com os dados do Saeb de 2003, serviram de base para que 0 indicador fosse calibrado e, assim, o ICP tendeu a ter maior peso no resultado do indicador, bem como os salários das professoras e diretoras ${ }^{4}$. Os pesos das outras variáveis dos indicadores parciais seguiram a mesma metodologia.

Em relação ao aspecto qualitativo Gouveia, Souza e Schneider (2011) se basearam em Bresseoux (2003), Souza (2007) e Camargo (2006). A gestão escolar, por exemplo, que corresponde apenas a $10 \%$ do quantitativo do ICQ, foi definida como tal não por ter menor importância nas condições de qualidade, mas fundamentado no entendimento de que a gestão escolar perpassa por todas as outras dimensões dos indicadores parciais. Ou seja, a gestão é entendida como um elemento mediador e mobilizador dos outros indicadores e, também, como parte componente deles, tendo em vista que os outros indicadores parciais - ICP e ICME - se relacionam e contemplam a gestão, ainda que seja difícil mensurar o tamanho ou efeito desta relação.

Do mesmo modo é necessário problematizar o ICME, tendo em vista que ainda que as condições materiais sejam fundamentais para pensar as $C Q$, se não tivermos uma professora com formação e motivada para fazer uso dos instrumentos, equipamentos eletrônicos e demais materiais que podem auxiliar em uma aula de qualidade, as condições tem pouca utilidade. Deste modo o ICME corresponde a $30 \%$ do valor do ICQ, baseando-se na justificativa de que a efetivação do bom uso de tal materialidade está diretamente ligada à ação da professora.

\footnotetext{
${ }^{4}$ Em Gouveia, Souza e Schneider (2011) há maiores esclarecimentos técnicos a respeito das correlações
} de Pearson realizadas. 
O ICQ tem seus limites e eles se referem as informações disponíveis na base de dados fomentadora do índice: os questionários da Prova Brasil de 2017 e a própria formulação do indicador. Ainda assim, por meio dele, é possível captar e quantificar aspectos reconhecidamente importantes e influentes na oferta educacional com qualidade.

\section{Resultados}

O Estado do Paraná é composto por 399 municípios e destes 397 tiveram seus dados divulgados em relação a Prova Brasil de 2017. Dois municípios - Porto Rico e Santa Cruz de Monte Castelo - ficaram de fora da análise por não apresentarem os dados para a composição dos indicadores. Destes 397 municípios foram analisados os dados de 2.527 escolas e 7.897 professores. É importante destacar que se optou por trabalhar apenas com as informações das escolas que não apresentam código máscara ${ }^{5}$ na sua identificação.

A composição do ICQ e de cada indicador parcial foi feita a partir dos questionários respondidos por um sujeito diferente no processo de aplicação da Prova Brasil. Nesse sentido a tabela a seguir apresenta o cálculo da média, mediana, desvio padrão, mínimo e máximo para o ICQ e cada indicador parcial.

Tabela 1 -

Estatísticas descritivas do ICQ das escolas de ensino fundamental dos anos iniciais dos municípios paranaenses.

\begin{tabular}{l|c|c|c|c}
\hline \multicolumn{1}{c|}{ Estatística } & ICP & ICME & ICG & ICQ \\
\hline Média & 0,57 & 0,75 & 0,61 & 0,63 \\
\hline Mediana & 0,57 & 0,75 & 0,61 & 0,62 \\
\hline Desvio padrão & 0,06 & 0,11 & 0,08 & 0,05 \\
\hline Mínimo & 0,3 & 0,22 & 0,32 & 0,48 \\
\hline Máximo & 0,77 & 0,96 & 0,83 & 0,79 \\
\hline
\end{tabular}

Fonte: autora (2021).

O ICQ apresenta a média e mediana bastante próximas, com diferenças milésimas. A tabela revela que a referida média dos resultados do ICQ dos anos iniciais ofertados pelos municípios paranaenses é de 0,63 , na escala de 0 a 1 . Além disso a variação entre o mais alto ICQ para o de mais baixo é de $39 \%$, o que representa 0,31 pontos.

A partir da tabela 1 também é possível constatar que o ICP possui a média e a mediana bastante próximas. Ele é o indicador que possui a menor média quando comparado com os outros indicadores parciais e a diferença entre o município que

\footnotetext{
${ }^{5}$ As orientações para a leitura dos microdados da Prova Brasil de 2017, no item 6, definem o mascaramento das bases. De acordo com o documento "as máscaras, entendidas como códigos fictícios, foram utilizadas em todas as bases para evitar a identificação de escolas e municípios cujos resultados não podiam ser publicados" (Inep, 2017, p. 9) tendo em vista as regras descritas no item 5 do referido documento. "O uso das máscaras nesses casos não ocorreu de maneira simultânea, de modo que, se o município foi mascarado, necessariamente todas as suas escolas também foram. [...] Nas bases de escola, diretor e professor, a escola, que participou somente da Aneb ou que seus resultados não podiam ser publicados, teve seu código mascarado" (Inep, 2017, p. 10). 
apresenta o resultado mais alto do ICP para o mais baixo é de 0,47 pontos, ou seja, este último município apresenta um indicador $61 \%$ menor que o maior indicador. Em linhas gerais as condições do professor representam o indicador parcial mais frágil levando em conta as três médias.

O ICME é o indicador que apresenta a média mais alta e, igualmente ao ICG, este resultado é próximo a mediana. Por sua vez é importante destacar que a média é um tipo medida de centralidade, ou seja, ela não evidencia os extremos e é facilmente distorcida por valores extremamente altos e baixos. Tal consideração se confirma ao observar que o desvio padrão deste indicador parcial é o mais alto entre os indicadores, de 0,11 pontos, e o mínimo e máximo apresentam 0,74 pontos de diferença. Assim, ainda que este seja o indicador parcial de média mais alta, ele é também o de maior disparidade, o que revela um cenário regional de desigualdade de condições materiais.

O ICG é o indicador que possui a segunda maior média dentre os indicadores parciais, sendo que a sua mediana é igual a média. Além disso, a diferença entre o resultado do município de maior indicador, para o de menor indicador, é de 0,51 pontos, ou seja, trata-se também da segunda maior diferença quando comparado ao ICP e ICME, evidenciando um cenário de desigualdade que se confirma ao observar o alto desvio padrão indicador. As condições de gestão, a nível nacional, conforme Silva (2017), corresponde a categoria onde há maior disparidade de resultados, quadro este que não se estende para o cenário dos municípios do Estado do Paraná, onde o indicador de maior disparidade é o ICME.

Feitos estes destaques gerais das condições de qualidade das redes municipais de ensino fundamental paranaenses é importante visualizar de forma mais cuidadosa os seus componentes, a fim de melhor captar e interpretar a realidade educacional em suas diversas dimensões. Assim, o próximo item se dedica a analisar o panorama geral do ICP, do ICME e do ICG.

\section{Panorama dos índices parciais do ICQ: ICP, ICME e ICG}

Para melhor entendimento do ICQ é preciso examinar as variáveis que influenciam o resultado. Assim, o primeiro indicador a ser analisado é o Índice de Condições do Professor. Tal indicador é composto por quatro variáveis que tem seus resultados expostos em termos estatísticos na tabela a seguir.

Tabela 2 -

Panorama dos resultados do ICP nos municípios paranaenses.

\begin{tabular}{l|c|c|c|c|c}
\hline $\begin{array}{c}\text { Descrição dos } \\
\text { dados }\end{array}$ & $\begin{array}{c}\text { Escolaridade } \\
(\mathrm{V} 1)\end{array}$ & $\begin{array}{c}\text { Salário por 40 } \\
\text { horas (V2) }\end{array}$ & $\begin{array}{c}\text { Experiência } \\
(\mathrm{V} 3)\end{array}$ & $\begin{array}{c}\text { Situação } \\
\text { trabalhista (V4) }\end{array}$ & ICP \\
\hline Média & 0,78 & 0,33 & 0,74 & 0,9 & 0,57 \\
\hline Mediana & 0,84 & 0,32 & 0,75 & 0,97 & 0,57 \\
\hline Desvio padrão & 0,08 & 0,08 & 0,18 & 0,14 & 0,06 \\
\hline Mínimo & 0,5 & 0,13 & 0 & 0 & 0,3 \\
\hline Máximo & 0,95 & 0,62 & 1 & 1 & 0,77 \\
\hline
\end{tabular}

Fonte: autora (2021). 
A V2, indicador de salário por 40 horas, corresponde a variável de maior impacto em termos de resultados numéricos no ICP. Por se tratar de uma média ponderada, esta variável tem metade do valor numérico do indicador parcial, uma vez que possui peso 4 . Isso se deve ao fato desta dimensão ser fundamental para se pensar as condições de qualidade do trabalho docente e a efetividade da V3 - indicador de experiência - e V4 indicador de situação trabalhista. Este é o indicador que apresenta a menor média entre as variáveis, de 0,33 . Este dado revela que em média os salários dos professores dos municípios paranaenses, com uma jornada de 40 horas, estão situados na faixa de $R \$$ $2.811,01$ até $R \$ 3.279,50$ e o que significa que, em média, os salários estão acima do $\mathrm{PSPN}^{6}$. Por sua vez, ainda existem municípios que com faixa salarial abaixo do piso nacional, conforme revela o mínimo atingido na variável, de 0,13 , o que representa que 0 salário destes municípios é 4,7 vezes inferior que os maiores salários.

De acordo com a meta 18 do Plano Nacional de Educação, no prazo de dois anos de sua vigência, ou seja, meados de 2016, os profissionais da educação básica e superior deveriam estar assegurados por plano de carreira que garantisse o piso salarial nacional profissional. Entretanto, conforme revela esta pesquisa, a meta ainda não foi alcançada em todos os municípios paranaenses.

$\mathrm{O}$ indicador de escolaridade é contemplado na V1. Esta é a variável de segunda maior média, de 0,78 e mediana de 0,84. Estes valores indicam que, em média, os professores que responderam o questionário que fomenta o ICP estão situados na faixa dos profissionais que possuem ensino superior. Entretanto, não é possível afirmar com exatidão a escolaridade apenas com base no resultado numérico, tendo em vista que este indicador é produzido por uma variável com uma ou mais respostas por escola.

A V3, indicador de experiência, possui o maior desvio padrão, o que indica maiores desigualdades em seus resultados. Esse dado revela a diversidade de professores com anos de experiência variados, o que se confirma ao recorrer ao mínimo e ao máximo da variável. Enquanto existem professores no primeiro ano de experiência, outros possuem mais de 20 anos de carreira.

O indicador de situação trabalhista também apresenta um desvio padrão alto, o que revela vínculos empregatícios diversos entre os professores dos municípios da amostra. De igual modo que o 'indicador de experiência' os valores mínimo e máximo atingem os extremos, pensando na escala de 0 a 1 que quantifica o indicador. Está é a variável de maior média, 0,90, e com mediana maior que o valor supracitado, de 0,97: este dado revela que em média estes profissionais possuem contratos de trabalho por concurso ou vinculada por CLT. O ICP corresponde ao indicador parcial de menor média entre os indicadores, ficando inclusive abaixo da média do ICQ dos municípios. Desse modo, as condições de trabalho do professor são as mais frágeis se considerados os valores médios dos outros índices. Por meio da tabela 2 é possível constatar que a variável mais alarmante consiste no 'indicador de salário por 40 horas', o que revela a desigualdade de investimentos que os municípios fazem em termos de remuneração docente.

${ }^{6}$ O piso salarial para o ano de 2017 era de $R \$ 2.298,80$. Atualmente o piso é de $R \$ 2.455,35$. 
O segundo indicador parcial, o ICME, representa $30 \%$ do total mensurado no indicador de base da metodologia e é composto por quatro variáveis que estão expostas na tabela $3 \mathrm{com}$ os dados iniciais que auxiliam no entendimento das condições de qualidade.

Tabela 3 -

Panorama dos resultados do ICME nos municípios paranaenses.

\begin{tabular}{l|c|c|c|c|c}
\hline $\begin{array}{c}\text { Descrição dos } \\
\text { dados }\end{array}$ & $\begin{array}{c}\text { Iluminação e } \\
\text { ventilação (V1) }\end{array}$ & $\begin{array}{c}\text { Conservação } \\
\text { das condições } \\
\text { físicas (V2) }\end{array}$ & $\begin{array}{c}\text { Computadores } \\
\text { e internet (V3) }\end{array}$ & $\begin{array}{c}\text { Equipamentos } \\
\text { eletrônicos (V4) }\end{array}$ & ICME \\
\hline Média & 0,82 & 0,86 & 0,63 & 0,78 & 0,75 \\
\hline Mediana & 0,83 & 0,87 & 0,63 & 0,8 & 0,76 \\
\hline Desvio padrão & 0,1 & 0,13 & 0,15 & 0,15 & 0,1 \\
\hline Mínimo & 0,36 & 0 & 0 & 0 & 0,22 \\
\hline Máximo & 1 & 1 & 0,98 & 1 & 0,96 \\
\hline
\end{tabular}

Fonte: autora (2021).

A média e mediana da V2 - 'indicador de iluminação e ventilação' - é a maior dentre as quatro variáveis e apresenta um desvio padrão alto, o que evidencia que em se tratando das condições de iluminação e ventilação das escolas que compõem a amostra há grande desigualdade, afirmação esta que se confirma ao recorrer ao mínimo e máximo alcançado na variável, onde existe diferença de $100 \%$, ou seja, enquanto uma rede apresenta a totalidade de condições de iluminação e ventilação em qualidade, atingindo 0 máximo da escala de 0 a 1, em outras há ausência completa de condições da V2. Este quadro se repete também no 'indicador de computadores e internet' (V3) e no 'indicador de equipamentos eletrônicos' (V4).

A V1 - 'indicador de conservação das condições físicas' - é a única variável que não dispõe do valor mínimo atingido igual a zero. Ainda assim alguns municípios apresentam quase o triplo de condições físicas de conservação das suas escolas em relação a outros municípios. Esta é a variável de segunda maior média e mediana. Já a V3, que consiste nas condições para computadores e internet, possui o maior desvio padrão entre as variáveis e a menor média. Ela é a única variável que não atingiu o máximo da escala. Além disso é possível observar que esta é a dimensão da ICME em que existe maior fragilidade nas escolas de ensino fundamental dos municípios paranaenses.

O 'indicador de equipamentos eletrônicos' (V4) possui um desvio padrão muito próximo ao da $\mathrm{V} 3$ e a diferença entre o município de menor índice parcial nesta variável para o de maior índice é de $100 \%$. Desse modo a V4 também representa um cenário onde há desigualdade grande entre os municípios.

A existência de uma estrutura física adequada e bem conservada, bons materiais e equipamentos não implica numa relação direta para 0 melhor desempenho dos estudantes. É preciso fazer a ressalva de que esta materialidade é mediada e utilizada pelos professores e alunos, de modo que se o uso não for feito ou se não for feito de maneira correta ele tem pouca condição de contribuir com o processo de ensino e, num cenário em que o ICP corresponde ao indicador mais frágil, cumpre questionar o quanto 
destes dados do ICME se transformam, efetivamente, em qualidade. Por sua vez o contrário, o que significa a ausência desta materialidade ou ainda a sua má conservação, tem muito mais possibilidades de interferir direta e negativamente nas condições de qualidade da escola e, portanto, no processo de aprendizagem do estudante.

Embora o ICME seja o indicador de maior média ele é também o indicador em que há mais alta disparidade de resultados, o que revela um cenário de desigualdade de condições em termos estruturais e materiais nas redes municipais. Assim, esta é uma dimensão das condições de qualidade em que há grande necessidade da ação do Estado com políticas focalizadas na melhoria da infraestrutura e da materialidade presente nas escolas. Conforme destaca Neto et al. (2013) é importante se atentar para os fatores contextuais passíveis de intervenção, como as condições materiais, que possam trazer melhorias para o sistema educacional de modo a viabilizar o aprendizado, além de favorecer as interações humanas.

O último indicador parcial que compõe o ICQ consiste no 'índice de condições de gestão'. O ICG corresponde a $10 \%$ do total do indicador de base da metodologia utilizada, tendo em vista a compreensão de que esta é uma dimensão que perpassa os outros indicadores parciais, ou seja, a gestão é entendida como elemento mediador e mobilizador dos outros aspectos tratados anteriormente, ainda que seja difícil mensurar o efeito desta relação existente da gestão no ICP e o ICME.

Este indicador é fomentado por questões mais objetivas e cada variável envolve somente uma pergunta do questionário de contexto do diretor. Ademais, é importante mencionar que os aspectos avaliados estão relacionados à gestão democrática do ensino, por sua vez, a regulamentação destas dimensões advém das políticas educacionais da gestão da educação da rede municipal. Assim, a elaboração da proposta pedagógica, a forma de provimento do cargo do diretor e a existência de conselhos de escola tendem a ser normatizadas em toda a rede, ainda que a execução da política de forma democrática dependa e esteja ligada a forma como estas questões são conduzidas por parte da escola, o que significa que embora as escolas estejam submetidas à mesma legislação do município correspondente, dentro da mesma rede é possível encontrar resultados distintos.

Tabela 4 -

Panorama dos resultados do ICG nos municípios paranaenses.

\begin{tabular}{l|c|c|c|c|c}
\hline $\begin{array}{l}\text { Descrição dos } \\
\text { dados }\end{array}$ & $\begin{array}{c}\text { Salário do } \\
\text { diretor (V1) }\end{array}$ & $\begin{array}{c}\text { Forma de } \\
\text { provimento do } \\
\text { cargo (V2) }\end{array}$ & $\begin{array}{c}\text { Conselho de } \\
\text { escola (V3) }\end{array}$ & $\begin{array}{c}\text { Projeto político- } \\
\text { pedagógico } \\
\text { (V4) }\end{array}$ & ICG \\
\hline Média & 0,54 & 0,73 & 0,7 & 0,53 & 0,61 \\
\hline Mediana & 0,54 & 0,71 & 0,72 & 0,53 & 0,61 \\
\hline Desvio padrão & 0,09 & 0,18 & 0,17 & 0,16 & 0,08 \\
\hline Mínimo & 0,21 & 0,13 & 0,25 & 0,24 & 0,32 \\
\hline Máximo & 1 & 1 & 1 & 1 & 0,83 \\
\hline
\end{tabular}

Fonte: autora (2021).

A tabela do panorama dos resultados do ICG nos municípios paranaenses apresenta variáveis com desvio padrão alto, o que revela um cenário de desigualdade alta nas dimensões da gestão democrática tratadas no indicador. A V1, que avalia o salário do 
diretor, corresponde a segunda menor média das variáveis, entretanto, esta é a dimensão em que há o menor desvio padrão, o que significa que dentre as questões contempladas do ICG, na remuneração do diretor é onde existe menor dispersão de resultados, sendo que a média salarial está concentrada entre 0,45 e 0,6 , ou seja, $R \$ 3.748,01$ e $R \$$ $6.559,00$.

A V2, que diz respeito a forma de provimento do cargo, refere-se a variável de mais alta média, de 0,73. Entretanto, esta variável também apresenta o maior desvio padrão. Assim, é possível perceber que esta é a dimensão da gestão democrática em que há maior desigualdade entre as redes municipais paranaenses, o que evidencia distintas normatizações da forma de provimento do cargo de diretor entre as redes. Ainda que esta seja apenas uma das dimensões da gestão democrática, a forma de provimento do cargo é um passo importante para a ampliação, ou não, dos horizontes democráticos da gestão da escola, de modo que a eleição, que tem maior valor atribuído a quantificação, é entendida como um "instrumento que, potencialmente, permite à comunidade escolar controlar as ações do dirigente escolar no sentido de levá-lo a se comprometer com esse princípio" (Souza, 2007, p. 189).

O 'indicador de conselho de escola', expresso na V3, indica que dentre os municípios avaliados o mínimo atingido foi de 0,25. Dessa forma é possível constatar que, em média, as escolas dos municípios possuem este instrumento de gestão e que nos municípios de mais baixo resultado ele se reuniu pelo menos uma vez durante o ano. Ademais, a V3 indica que a média dos municípios em relação a quantidade de reuniões que ocorreram deste órgão colegiado foi de duas vezes por ano. Ainda assim este indicador possui um desvio padrão alto, o que indicada valores dispersos da quantidade de reuniões que ocorreram em média nas escolas. É importante destacar que o limite do dado deste indicador está na impossibilidade de medir se este órgão colegiado que envolve a comunidade escolar com representantes que auxiliam a tomada de decisões na escola foi, de fato, efetivo nas suas decisões.

A quarta variável do ICG, denominada 'indicador de projeto político-pedagógico', apresenta a menor média que releva que a maior parte das escolas dos municípios da amostra elaborou um modelo próprio de PPP, porém sem discussão com a equipe escolar. Ainda que em média não se tenha utilizado um modelo pronto deste documento, o que corresponde a um dado importante, tendo que em vista que este projeto deve ser pensado de acordo com a realidade de cada escola e dos sujeitos que nele estão envolvidos, a participação da equipe escolar é frágil. Assim, este documento perde o sentido público que tem de um projeto que pertence a todos e que deve ser construído coletivamente (Veiga, 2009). A participação limitada revela que os espaços de poder não são acessados democraticamente por aqueles que estão envolvidos nos processos escolares e que esta deve ser uma questão onde as oportunidades de participação devem ser ampliadas, tendo em vista que a participação é uma condição básica para a gestão democrática, o que significa que uma não é possível sem a outra.

\section{Considerações finais}

A análise das condições de qualidade das redes municipais do Paraná, com recorte nos anos iniciais do ensino fundamental, auxiliou a compreensão do panorama das $\mathrm{CQ}$ ofertadas nos municípios paranaenses, bem como a possibilidade de visualizar de forma 
mais sensível as desigualdades intraestaduais. O ICQ se mostrou uma ferramenta eficaz na avaliação da política educacional, conseguindo congregar de forma quantitativa as dimensões reconhecidamente importantes na literatura em termos de condições que oportunizam uma educação de qualidade.

Dessa forma, os resultados do ICQ relevam regularidade de condições de qualidade nas redes municipais paranaenses, que em média possuem professores com formação em ensino superior, com contratos de trabalho por concurso ou vinculados por CLT, escolas que reúnem condições razoáveis de conservação das instalações físicas e materiais e com certa participação dos profissionais e da comunidade escolar nos processos decisórios da escola. O ICME, apesar de ser o indicador de maior média, é também a dimensão em que há maior disparidade, o que revela que as condições materiais das escolas são muito diferenciadas, com destaque para a dispersão dos resultados em termos de acesso a computadores e internet. Tal cenário evidencia a necessidade de políticas educacionais que priorizem as condições materiais das escolas dos municípios no Paraná, de modo a construir um ambiente escolar onde os estudantes possam encontrar condições materiais que colaborem com a sua aprendizagem e sejam adequadas para o seu desenvolvimento saudável.

O ICP é o indicador que apresenta os piores dados. Existe uma disparidade grande em termos salariais nos municípios, o que reflete em condições do exercício da docência de forma desigual. Ainda que em média os salários estejam acima do PSPN, ainda existem municípios com faixa salarial abaixo do piso nacional, o que revela a urgência do cumprimento da meta 18 do Plano Nacional de Educação que determina que os profissionais da educação básica e superior devem estar assegurados por plano de carreira que garantem o piso salarial nacional profissional. Ademais, o salário do professor é, em média, 36\% menor que o salário do diretor.

O ICG apresenta a segunda maior média de resultados e o segundo menor desvio padrão, por sua vez, as variáveis que o compõem possuem alto desvio padrão, o que indica condições de gestão democrática diferenciadas entre as escolas dos municípios. Cabe destaque a maior dispersão presente na variável forma de provimento do cargo, de modo que esta consiste na dimensão em que há maior desigualdade entre as redes municipais paranaenses, ou seja, distintas normatizações da forma de provimento do cargo de diretor. Assim, cumpre destacar a importância da ampliação dos espaços de participação dos profissionais da educação e da comunidade escolar, a começar pela eleição do seu dirigente.

A metodologia utilizada possui limitações, entretanto, o ICQ foi um instrumento fundamental para analisar e problematizar as condições de qualidade e, a falta delas, nos municípios que compõem o Estado do Paraná, sinalizando onde há maior carência da ação do Estado na forma de políticas educacionais que corroborem com a elaboração de escolas em condições de qualidade que possibilitem a igualdade de oportunidades com equidade para os seus estudantes e profissionais que a constituem. Assim, são muitos e urgentes os desafios a serem superados para a garantia de insumos e condições adequadas para o cumprimento do direito à educação pública com qualidade. 


\section{Referências}

BRASIL. Constituição da República Federativa do Brasil. Brasília: Senado Federal, 1988. BRASIL. Emenda constitucional n. 59, de 11 de novembro de 2009. Brasília: DOU, 2009. BRASIL. Lei n. 13.005 de 25 de junho de 2014: aprova o Plano Nacional de Educação PNE - e dá outras providencias. Brasília: DOU, 2014.

BRASIL. Lei n. 9.394 de 20 de dezembro de 1996: estabelece a Lei de Diretrizes e bases da Educação Nacional. Brasília: DOU, 1996.

BEISEGEL, Celso de Rui. A qualidade do ensino na escola pública. Brasília: Liber Livro, 2005.

BRESSOUX, Pascal. As pesquisas sobre o efeito-escola e o efeito-professor. Educação em Revista, Belo Horizonte, n. 38, 2003, p. 17-88.

CAMARGO, Rubens Barbosa et al. Problematização do conceito de qualidade presente na pesquisa custo aluno ano em escolas de educação básica que oferecem condições para a oferta de um ensino de qualidade: relatório de pesquisa. Brasília: MEC/Inep, 2006.

CURY, Carlos Roberto Jamil. Qualidade da educação brasileira como um direito. Educ. Soc., Campinas, v. 35, n. 129, 2014, p. 1053-1066.

ENGUITA, Mariano. O discurso da qualidade e a qualidade do discurso. In: GENTILI, Pablo; SILVA, Tomaz (org.). Neoliberalismo, qualidade total e educação. Petrópolis: Vozes, 1997, p. 93-110.

FURTADO, Marcelo Gasque. Padrão de Qualidade do Ensino. In: RANIERI, Nina Beatriz Stocco. Direito à educação. São Paulo: USP, 2009, p.167-182.

GOUVEIA, Andréa Barbosa; SOUZA, Ângelo Ricardo; SCHNEIDER, Gabriela. Índice de condições de qualidade educacional: metodologia e indícios. Estudos em Avaliação Educacional, São Paulo, v. 22, n. 48, 2011, p. 115-135.

INSTITUTO NACIONAL DE ESTUDOS E PESQUISAS EDUCACIONAIS ANÍSIO TEIXEIRA. Brasília: Ministério da Educação, 2017.

NETO, Joaquin José Soares et al. Uma escala para medir a infraestrutura escolar. Est. Aval. Educ., São Paulo, v. 24, n. 54, 2013, p. 78-99.

NUPE. Políticas educacionais e qualidade de ensino, as relações entre o investimento financeiro em educação, as condições de qualidade, o perfil da demanda educacional e $o$ desempenho estudantil no Estado do Paraná: relatório de pesquisa. Curitiba: UFPR, 2007.

OLIVEIRA, Romualdo Portela de; ARAUJO, Gilda Cardoso de. Qualidade do ensino: uma nova dimensão da luta pelo direito à educação. Revista Brasileira de Educação, Rio de Janeiro, n. 28, 2005, p. 5-23.

SCHNEIDER, Gabriela. As ações do governo federal no âmbito das condições materiais e estruturais da escola: Uma problematização a partir do conceito de justiça social. Curitiba: UFPR, 2014. 246f. Tese (Doutorado em Educação). Universidade Federal do Paraná.

SILVA, Marcus Quintanilha. Condições de qualidade das redes municipais de ensino fundamental no Brasil. Curitiba: UFPR, 2017. 229f. Dissertação (Mestrado em Educação). Universidade Federal do Paraná.

SILVA, Maria Abadia. Qualidade social da educação pública: algumas aproximações. Cadernos Cedes, Campinas, v. 29, n. 78, 2009, p. 216-226. 
SOUZA, Ângelo Ricardo de Souza. Por que estudar políticas educacionais? In: SOUZA, Ângelo Ricardo de Souza; GOUVEIA, Andréa; TAVARES, Taís Moura (org.). Políticas educacionais: conceitos e debates. Curitiba: Appris, 2016, p. 13-21.

SOUZA, Ângelo. Perfil da gestão escolar no Brasil. São Paulo: PUCSP, 2007. 333f. Tese (Doutorado em Educação). Pontifícia Universidade Católica de São Paulo.

TAPOROSKY, Barbara Cristina Hanauer; SILVEIRA, Adriana Dragone. A qualidade da educação infantil como objeto de análise nas decisões judiciais. Educação em Revista, Belo Horizonte, v. 34, 2018, p. 1-31.

VEIGA, Ilma Passos Alencastro. Projeto político-pedagógico e gestão democrática: novos marcos para a educação de qualidade. Revista Retratos da Escola, Brasília, v. 3, n. 4, 2009, p. 163-171.

XIMENES, Salomão Barros. O conteúdo jurídico do princípio constitucional da garantia de padrão de qualidade do ensino: uma contribuição desde a teoria dos direitos fundamentais. Educ. Soc., Campinas, v. 35, n. 129, 2014, p. 1027-1051.

Gabriele Ferreira Barbosa é estudante no curso de Mestrado em Educação na Universidade Federal do Paraná.

Orcid: https://orcid.org/0000-0002-3846-5204.

Endereço: UFPR - Avenida Sete de Setembro, s/n - 81130-190 - Curitiba - PR Brasil.

E-mail: gabi.ferbar@hotmail.com.

Critérios de autoria: Gabriele Ferreira Barbosa concebeu, individualmente, a ideias, coleta e análise dos dados, a redação e a consolidação do artigo.

Recebido em 6 de março de 2021.

Aceito em 13 de julho de 2021.

(c) (1) $(9)$ 